\title{
Transferir tecnologia para outros espaços escolares
}

\author{
Technology transfer to other school spaces
}

\author{
Ángel San Martín Alonso** \\ Universitat de Valencia \\ José Peirats Chacón*** \\ Universitat de Valencia
}

Resumo O modelo de transferência de tecnologia oferece-nos uma perspectiva para analisarmos como as escolas recebem as inovações tecnológicas e seus equipamentos. Particularmente, consideramos as inovações geradas por esses processos no nível organizacional das escolas recebedoras dessas tecnologias. Os dados estudados decorrem de investigação atualmente realizada em doze (12) territórios autônomos espanhóis no Programa Escola 2.0. Nesta fase, estamos realizando a estatística descritiva e referências de algumas entrevistas e observações em centros escolares com docentes participantes do Programa "Centros Educativos Inteligentes". Dos primeiros resultados obtidos, podemos dizer que o sistema escolar segue um padrão de transferência incluindo: alta dependência da administração educativa, maior ênfase no equipamento instrumental do que no conhecimento e, finalmente, escassa formação prévia do centro receptor.

PALAVRAS-CHAVE: Transferência de tecnologia; Organização escolar; Políticas 1-1; Inovação tecnológica.

Abstract The technology transfer model offers us a perspective to analyze how schools receive incorporate technological activities and their equipment. Particularly, we analyze the innovations generated by these processes at the organizational level of schools as recipients of technology. The analyzed data belong to an investigation which is currently being performed in 12 regions on the "School 2.0 program". At this stage we handle references of descriptive statistics and some of the interviews and classroom observations from the participating centers on the "smart school". From the first analysis, it can be said that the school system follows a pattern transfer including: high dependence on the political level, more emphasis on the instrumental equipment than on knowledge and, finally, little previous preparation of the recipient organization.

KEYWORDS: Technology transfer; School organization; Policies 1-1; Technological innovation.

\footnotetext{
* Tradução realizada a partir de texto inédito, escrito originalmente em espanhol, intitulado "Transferir tecnología para otros espacios escolares" e, a pedido dos autores, traduzido para o português por Adriana Moreira da Rocha Veiga, professora do Programa de Pós-graduação em Educação, do Centro de Educação da Universidade Federal de Santa Maria.
} 
[...] na semente da cidade dos justos está escondida por sua vez uma semente maligna.

Italo Calvino

\section{Introdução}

A instituição escolar não permanece alheia às contingências de uma sociedade constituída em torno da "economia do conhecimento". Economia cujo principal motor é hoje, segundo estabelece a Organização para a Cooperação e Desenvolvimento Econômico - $\mathrm{OCDE}^{1}$ ou a Agenda de Lisboa ${ }^{2}$, a inovação centrada na geração de conhecimento e sua transferência. Neste contexto, se conceitualiza a transferência de tecnologia (TT adiante) como o protocolo mediante o qual os sistemas de inovação e desenvolvimento produzem invenções que logo se transferem às diferentes instâncias e organizações, entre as quais está a escolar. A TT alude, pois, ao "processo de transmissão do saber fazer (know-how, savoir faire), de conhecimentos científicos e/ou tecnológicos e de tecnologia de uma organização a outra" (JIMÉNEZ, 2003, p.1). De modo que este processo afeta por igual aos artefatos tanto materiais como imateriais ou simbólicos, convertendo a transferência em uma sorte de conhecimento aplicado em contextos distintos.

No que se refere aos sistemas escolares da TT, pode experimentar-se, como mínimo, em três âmbitos distintos, embora inter-relacionados: o âmbito do currículo (QUINTANILLA; ESCOBAR, 2011), o de recursos tecnológicos para o ensino e o que afetaria a organização e a gestão da instituição (SIGALÉS et al., 2008). Neste trabalho nos centraremos, principalmente, no segundo âmbito, entre outras razões, porque se inscreve em uma linha de reflexão (PEIRATS; SAN MARTÍN, 2011) e em um projeto de trabalho de campo mais amplo, que analisa a implantação do Programa Escola 2.0 do Ministério da Educação ${ }^{3}$.

Nosso propósito é estudar como se prepara e recebe o recurso tecnológico nos centros escolares. $\mathrm{E}$ o fazemos com um duplo propósito: explorar novas vias na busca de explicações complementares às aportadas pelos estudos que demonstram o baixo uso das Tecnologias da Informação e Comunicação - TIC, nos centros escolares, e, em segundo lugar, nos interessamos em conhecer como os programas de TT desestabilizam e alteram o funcionamento de rotina das organizações receptoras.

\section{A transferência nem sempre é inovação educativa}

Os programas de transferência incorporam todo tipo de tecnologia gerada por qualquer dos agentes integrados no ecossistema tecnocientífico. O que se transfere de uma organização a outra é o know-how, porém que, na realidade intangível, engloba produtos tão diferentes como: projetos de $\mathrm{I}+\mathrm{D}+\mathrm{i}^{4}$, computador, serviços, assistência técnica, produção de bens protegidos, exploração e desenvolvimento de patentes, mobilidade de pessoas, etc. A inovação e, portanto, a TT se produzem tanto no setor industrial como no de serviços, podendo afetar a: produtos, processos, posição do produto ou serviço no contexto e no paradigma, quando uma organização altera o modelo de produção do bem ou serviço que presta (COTEC, 2011). Em definitivo, a TT se "asu- 
me como un proceso central para la innovación y el desarrollo" (PINTO, 2012), tanto da organização como da atividade/produto implicado. Sem dúvida, parafraseando Stiglitz (2012, p. 79), a transferência por si só não gera, em todo caso, inovação e para Durall et al. (2012, p. 21) é ainda um "desafio" de futuro na educação.

Quanto a TT nos sistemas escolares, fenômeno antigo, embora agora intensificado com as TIC, a focalizamos sobre os meios para o ensino, interessando-nos por estes, mas também pela natureza das estratégias que são incorporadas pela organização receptora e, consequentemente, quais mudanças se adaptam na mesma. Pois, como observa Castells (2001, p. 121), o informacionismo gera uma nova forma de "estrutura social" ao mudar os dispositivos organizativos das relações de produção. Questões fundamentais de que nos ocuparemos nos parágrafos seguintes, a partir da avaliação de um caso de TT na Comunidade Valenciana.

Desde uma perspectiva mais ampla, os estudos promovidos pela OCDE mostram que "el 93\% de los alumnos de 15 años de edad de la OCDE asisten a una escuela en la que cuentan con acceso a un ordenador y prácticamente el mismo porcentaje $(92,6 \%)$ dispone igualmente de acceso a Internet ${ }^{6 \prime}$ (PEDRÓ, 2011, p. 17). No entanto, sob este mesmo trabalho, o computador que os estudantes têm em sua família é melhor do que o oferecido nas escolas, com um diferencial de 18 pontos percentuais em média em todos os países.

Outro estudo recente revela que $65 \%$ dos professores utilizam o computador/impressora "quase todos os dias" (BARQUÍN et al. 2011, p. 36). Sem dúvida, em uma porcentagem significativamente inferior (34\%), apesar de reconhecer valor didático na maior parte dessas novas ferramentas (86\%), o percentual admite a escassa incidência destes usos na aprendizagem dos estudantes. $\mathrm{O}$ citado terço de professores céticos responde a um perfil de docente jovem e com bom domínio do manejo destes meios. Bastante mais pessimista é a conclusão que, a partir dos dados da OCDE, extrai Pedró (2011, p. 22), no trabalho citado, quando afirma: "La tecnología no se usa en todas las materias con igual intensidad $y$, por consiguiente, hay un porcentaje elevado de materias en las cuales el nivel de integración es prácticamente inexistente [...]"7.

De modo que os agentes industriais transferem "produtos" tecnológicos aos sistemas escolares, a questão é se este produto satisfaz as expectativas de inovação alentadas pela iniciativa. $\mathrm{Na}$ maioria dos casos, só se transferem os equipamentos, não o conhecimento que envolve a implantação e desenvolvimento daqueles nas organizações educativas. Porém, a presença destes equipamentos, sobretudo os digitais, não são indiferentes às condições materiais, culturais e tecnológicas das organizações (LAM, 2000) ou a imposição de certos "totalitarismos cibernéticos" (LANIER, 2011). Sobre algumas das dimensões afetadas existem importantes análises, como os trabalhos sobre a alfabetização visual e digital (MESSARIS, 1994; BUCKINGHAM, 2008), sobre a percepção do espaço e tempo que tem os usuários das plataformas de e-learning (GARCÍA DEL DUJO et al., 2010) ou sobre a nova "morfologia do trabalho" (ANTUNES, 2012). 
Não obstante, a trama organizativa dos centros escolares, na medida que se articula conforme uma tecnologia de processo específica (ALCAIDE CASTRO, 1982), torna-se crucial para entender como se incorporam naqueles meios transferidos. Extremo que através de estudos em outras organizações, e trabalhos como os de Gurrutxaga (2010) ou Johnson (2011) têm mostrado. De maneira que parece oportuno deter-se a revisar com detalhe em que medida a TT leva em consideração a permeabilidade das organizações escolares. Razão pela qual o projeto dos Centros Educativos Inteligentes (CEI a seguir) resulta relevante ao enfatizar o centro como totalidade.

\section{São os CEI valencianos um caso de transferência de tecnologia?}

A intervenção política na implementação dos programas de TT é uma evidência, em que adicionalmente afeta os sistemas educativos. De fato, o Departamento de Educação Valenciana não se adere, em 2009, ao Programa Escuela 2.0 , promovido pela administração central. Alega para justificar tal decisão, entre outros argumentos, não ter sido consultado sobre uma proposta com importantes repercusões econômicas e políticas. Em particular e com respeito a este último, a Direção Geral de Inovação Tecnológica sublinhou que a iniciativa prejudicou o trabalho realizado no desenvolvimento de projetos próprios, tais como: ITACA, Mes-TI e, especialmente, o Lliure $X^{9}$ baseado em software livre. Se assinala, por outro lado, como argumento crítico, que o plano ministerial requeria infraestrutura com capacidade suficiente para suportar os novos equipamentos. No curso 2009-2010, eram já cerca de 100.000 computadores instalados nos centros educativos valencianos e a nova oferta representava aproximadamente outros 50.000 mais. Em apreciação da administração autonôma, a implantação da iniciativa ministerial gerava problemas e, sobretudo, se desviava das diretrizes adotadas desde o Departamento.

Neste contexto, a Generalitat Valenciana ${ }^{10}$ propõe, como plano alternativo ao Escola 2.0, o não menos controvertido projeto Centro Educativo Inteligente. $\mathrm{O}$ ambicioso objetivo do mesmo é o de integrar as TIC na totalidade de espaços constitutivos dos centros escolares. Durante o curso 2009/2010, foi lançado, como centros piloto, um Centro de Ação Educativa Singular (CAES) de Educação Infantil e Primária, assim como um Instituto de Educação Secundária ${ }^{11}$. No curso 2010/2011, outros 16 centros, tanto de Primária como de Secundária, se somaram na fase de implementação.

Neste tipo de centro, cada sala de aula comum tem um computador (thin client) para o professor como apoio a sua tarefa docente, uma vez que permitirá acesso aos recursos digitais educacionais (servidor central ou na Internet), e vai permitir realizar gestão administrativa e acadêmica mediante a aplicação de ITACA ${ }^{12}$ (passar lista, atrasos, incidências, notas, etc.); um quadro digital interativo que permitirá expor conteúdos educativos de forma coletiva; mais um projetor e accesso à Internet, apesar da pouca conectividade de muitos centros públicos valencianos (PANIAGUA FUENTES, 2010, p. 115).

Se esta breve descrição contrastar com o modelo de Rubiralta Alcañiz (2004, p. 17) para a análise da TT, observamos que a estrutura sobre a qual se sustenta 
o projeto CEI no Departamento de Educação do Governo Valenciano que, através da Direção Geral de Inovação Tecnológica, coordena a implantação em seu entorno imediato do projeto citado, se fortalece ao contar com SMART Board como parceiro tecnológico, multinacional que comercializa os quadros interativos, ademais de outras empresas "matrizes" de corporações do setor. No que se refere aos computadores "thin client", o provedor é Inves, fabricante dos mesmos e pertencente ao grupo comercial El Corte Inglés.

Em segundo lugar, a estrutura se consolida, segundo Rubiralta Alcañiz (2004), ativando instrumentos, tais como contratos, cessão de licenças, mobilidade de pessoal, serviços de apoio, etc. No caso que nos ocupa, se dota os centros que participam no projeto com computadores clientes, computadores portáteis, servidores de aula e de centro, lousas digitais. Oferta acompanhada de software educativo, material didático, formação dos professores, redes de intercâmbio de experiências, licenças de usuários e serviços de manutenção, etc. Os centros do projeto contam com o apoio, além do coordenador ou coordenadora TIC pertencente ao claustro, com os técnicos do serviço de Suporte e Assistência Informática $(\mathrm{SAI})^{13}$, a equipe técnica de apoio ao programa e várias empresas que prestam serviço especializado aos centros mais distantes das capitais. Da mesma forma que outros governos autônomos, o Governo Valenciano tem generalizado na rede de centros o uso de software livre (Lliurex), que tem causado problemas consideráveis de operacionalidade, especialmente no caso dos ciclos de formação profissional.

O terceiro elemento do modelo de Rubiralta Alcañiz (2004) é a participação ou a implicação dos diferentes atores. Pela natureza das organizações que nos ocupam, esta é uma dimensão fundamental, na medida que se externalizam certas tarefas e, em sua execução, se implica novos atores, nem sempre relacionados com a educação nem vinculados ao centro. Todo o qual configura um complexo entremeado de relações com pontos críticos com respeito à eficiência. Os projetos, em tais circunstâncias, responderiam ao padrão do "modelo mediterrâneo" de TT, segundo Rubiralta. Em definitivo e seguindo Aceytuno e Cáceres (2011, p. 11), o projeto CEI se configura como subsistema local (se deslocando do ministerial e se circunscrevendo a 18 centros da Comunidade Valenciana), aproveita sinergias em ocasiões informais (dos municípios, por exemplo). Forte na transferência não são tanto as patentes que geram, como a proliferação de publicações, estudos, congressos ${ }^{14}$, etc.

\section{Esboço metodológico}

Desde a perspectiva de estudo avaliativo de casos (STAKE, 2010), analisamos aqui como a articulação dos programas de TT e sua gestão no âmbito educativo geram demasiados efeitos imprevistos e poucos na direção que os motiva. Se ativam protocolos de TT sem preparação prévia da instância receptora, tanto no plano institucional como no organizativo. Desde esta consideração, nos propomos os seguintes objetivos:

a) Identificar o grau de aceitação dos recursos transferidos entre os membros da instituição escolar. 
b) Caracterizar o perfil de uso que se faz nos centros dos meios recebidos.

c) Descrever a incidência da TT sobre as condições funcionais da organização dos centros.

A população objeto de estudo são 18 centros de primária e secundária que participam no projeto CEI da Comunidade Valenciana (CV a partir daqui). Como já se tem apontado, os dados que manejamos se desagregam dos obtidos no estudo geral realizado nos centros de 12 comunidades autônomas; a maioria participa no plano Escola 2.0, a exceção de Madrid e Valência que desenham um plano próprio. O questionário foi elaborado pela equipe de investigação, seguindo o protocolo habitual para sua validação que se alojou no espaço web cedido a tal propósito pelo ITE (Ministério de Educação). A aplicação só se podia acessar com uma senha específica para cada território que, no caso da CV, se facilitou aos CEI através da Direção Geral de Inovação Tecnológica. O período para respondê-lo foi estabecido para toda a amostra entre os meses de abril e maio de 2011, transcorrido este período se encerrou o acesso.

A partir deste momento, o ITE entregou o conjunto de dados ao responsável pelo projeto para seu tratamento estatístico. Como é lógico, o preenchimento do questionário era a critério dos membros dos vários órgãos representativos, ainda recolhidos 4.421 questionários, dos quais 193 corresponden à $\mathrm{CV}^{15}$. Logo, os dados tem sido tratados em conjunto e segmentados por comunidades, para tal, se tem utilizado o programa SPSS.18 win. As estatísticas descritivas são complementadas pela análise das entrevistas e grupos de discussão realizados em quatro centros com cargos diretivos, coordenadores, professores e estudantes. Sobre esta base, apresentamos e discutimos os primeiros resultados sobre os CEI valencianos.

\section{Exposição e comentário de resultados}

Desagregados os dados, a amostra autonôma constitui-se de 193 questionários válidos de professoras e professores. Cabe destacar que foram preenchidos questionários nos 18 centros que participam no projeto valenciano, dos quais 11 são de Infantil e Primária (entre CEIP, CRA e CAES) e 7 institutos de Secundária, alguns destes com Ciclos Formativos de FP. A amostra de professores participantes se situa nos intervalos intermédios em idade e experiência profissional, e tem mais professores de Primária que de Secundária. A partir dos dados fornecidos por este instrumento, tratamos de interpretar tanto o tipo de tecnologia que se transfere como as estratégias organizativas e políticas que acompanham o processo.

\section{O centro determina o padrão de uso da TT?}

Talvez o fenômeno mais complexo de compreender e gerenciar que encontramos foi como as estruturas e processos organizacionais absorvem os modos de operar das tecnologias digitais. Entre outras razões, porque cada organização tem a sua própria força e isso incentiva a resistência ao novo chegando de fora, limitando seu potencial de inovação (MOMINÓ et al, 2008). De momento, segundo temos podido observar, convivem pautas de organização do trabalho típicas do fordismo 
junto a outras propriamente posfordistas. Questões que de algum modo subjazem nas respostas que os entrevistados dão ao ítem 16 , com respeito às diferentes dimensões da organização e que recolhemos na figura seguinte.

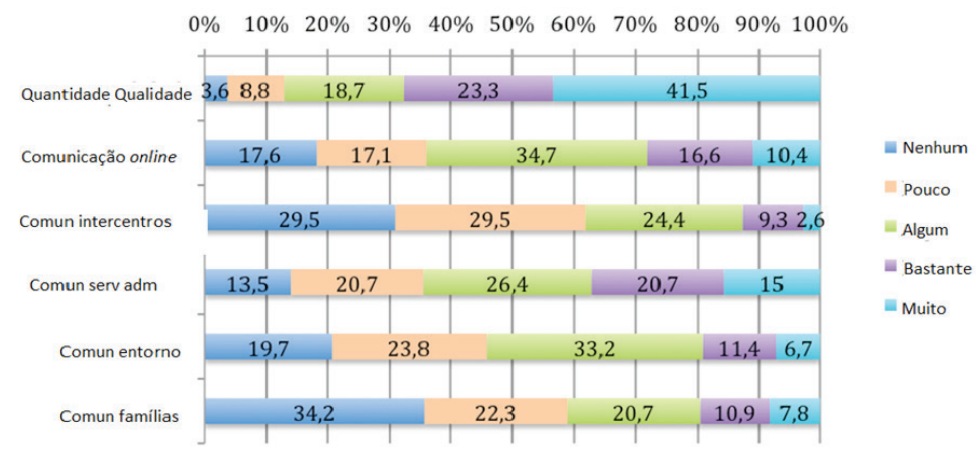

Figura 1 - Avaliação do impacto do programa sobre o centro.

Como reconhecido na amostra estatal, a $\mathrm{CV}$ admite, em uma alta porcentagem, que a maior contribuição do programa CEI consiste em "melhorar a quantidade e qualidade das TIC no centro". Por outro lado, algo mais de um terço admite que o programa não tem contribuido nada para incrementar "a comunicação entre os professores e as famílias". Cerca de $60 \%$ dos entrevistados reconhece que o dito programa tem contribuido pouco ou nada a aumentar "o contato e comunicação com outros centros educativos através da Internet". A "comunicação on-line entre os professores do centro" e a comunicação "do centro com outras instituições" do entorno social só um terço respectivamente reconhece que tenha melhorado "algo".

Mas se não foi detectado "ganho" em relação ao desempenho específico das tecnologias transferidas, o que passa em sua relação com a Administração? Como se retira da Figura 1, só uns 15\% valoram que se tem melhorado "muito" a comunicação dos docentes com as diferentes instâncias da Administração educativa. Enquanto uns $34,2 \%$ consideram que a melhoria neste plano é "nenhuma" ou "pouca". O diretor de um CEI de primária argumentava: "Que dúvida cabe que, antes com o GESCEN e agora como ITACA, enquanto segue dando alguns problemas, nos facilita muito as tarefas burocráticas... (sorrisos). Bom, assim também nos controlam mais do Ministério [ ] Enfim, onde não vejo tão clara sua utilização é nas aulas [ ]" (ED-4).

$\mathrm{O}$ padrão de resposta seguido pelos entrevistados na $\mathrm{CV}$ é muito similar ao demonstrado pelo total da amostra do estudo. O que mais chama à atenção dos professores é a melhora do equipamento, sem que logo o potencial destes meios se desenvolva em parecido grau no "que fazer" docente. Desde logo, surpreende que aquilo que dávamos por suposto ao começo resulte questionado pelos dados. Os novos equipamentos, segundo apreciam os professores entrevistados, não contribuem para melhorar o que é quase constitutivo das organizações, incluídas as escolares. 


\section{Função mediadora da coordenação TIC}

Este aparente desajuste detectado poderia ter a ver com a falta de apoio para exercer as novas tarefas requeridas pelo equipamento recebido? Em tal sentido, cabe perguntar-se pelas funções que desempenha o coordenador $\mathrm{TIC}^{16}$. Questões sobre as quais a figura seguinte aporta alguma luz.

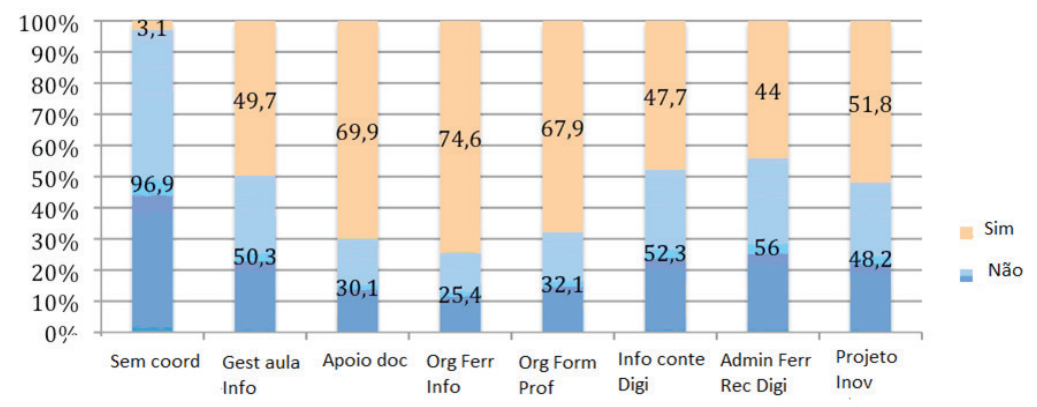

Figura 2 - Funções da coordenação.

Por agora, quase todos os professores têm reconhecido contar com o coordenador TIC no centro. Na verdade, o diretor de um instituto nos disse: "Antes de pedir ao Ministério ser CEI me assegurei que o profesor X aceitara ser o coordenador TIC [...]. Está tão entusiasmado que sem ele tudo isto não seria possível"(ED-1). De todos os modos, sua figura e funções tem muitas arestas que resultam controvertidas organizativamente (PEIRATS; SALES; SAN MARTÍN, 2007).

Em qualquer caso, segundo os dados da figura precedente, as três funções que sinalizam em torno da metade dos entrevistados são as seguintes: "atualizar e administrar os recursos e ferramentas informáticas" (74,6\%), ajudar "aos professores no desenvolvimento da docência com TIC" $(69,9 \%)$ e, em terceiro lugar, "organizar a formação dos professores sobre TIC no centro" (67,9\%).

Chama a atenção que entre as funções da coordenação se destaque a instrumental, porém não muito distante se sinalizam outras duas de orientação claramente pedagógica, em sentido amplo. De modo que, no fundo, os entrevistados assumem o papel "didático" das TIC e, consequentemente, valorizam o apoio que desde a coordenação lhes é dado nesse sentido.

Respostas que demonstram alto consenso entre os entrevistados em torno da relevância da função de coordenação nos CEI. Nada menos que 89,1\% considera "muito necessária" ou "bastante necessária" sua presença para "impulsionar e melhorar o uso das tecnologias". Não há dúvida de que a tecnologia está se tornando mais amigável, mas mais complexa de usar, portanto, o apoio de especialistas também se torna mais necessário, a fim de otimizar o desempenho de tais equipamentos. Supõe, definitivamente, integrar ao corpo docente dos centros escolares um novo especialista, valorizado mais pelo domínio das novas ferramentas que pelos conteúdos curriculares e, inclusive, os metodológicos. 


\section{A política inerente a TT nos CEI}

Como pode ser visto na Figura 3, quase três quartos dos professores pesquisados expressou "bastante" ou "concordam fortemente" que a modernização da educação requer oferta de tecnologia em sala de aula. Sem dúvida, se mostram mais reticentes a que em seguida se faça a oferta de um computador a todos os estudantes, tão somente uns $31 \%$ estaria "muito de acordo" com esta medida. É possível, não obstante, que os entrevistados expressem, deste modo, seu desacordo com a decisão da Administração Valenciana de não apostar no modelo 1-1. De fato, em continuação reconhecem não estar demasiado de acordo com a política seguida a respeito na $\mathrm{CV}$ (uns 38,8\% está nada ou pouco de acordo). Como é que, associando a modernização com o equipamento, em seguida se retraem a respeito do plano que dá a cada aluno um computador? Talvez seja porque eles não tenham preparado o suficiente os atores da organização receptora, condição necessária na TT?

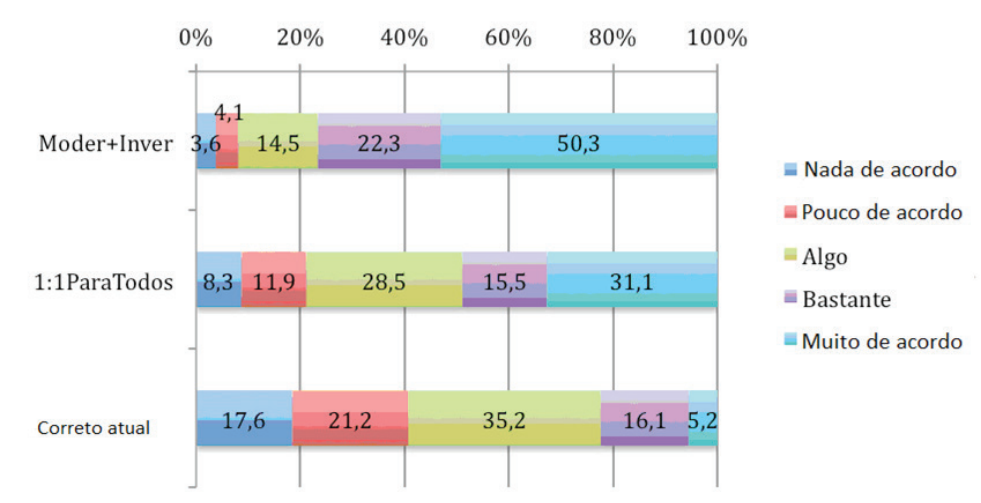

Figura 3 - Avaliação da política TIC na CV.

As organizações são "sistemas de interpretação e aprendizagem", concepção que supera a "visão determinista" da tecnologia, especialmente, quando os atores interagem com as forças tecnológicas do entorno (LAM, 2000). De modo que o processo de TT deve dar oportunidade para que os atores implicados reflitam e atribuam significado ao que se lhes propõem, à tecnologia que se lhes proporciona. Porém, no caso que nos ocupa, não parece que se lhes haja dado esta oportunidade. Ao menos é isto o que se depreende das palavras de um coordenador TIC: "A única explicação que encontro para não participar no programa do Ministério, é o resentimento que tem a administração daqui e a central. Ao final estão fazendo o mesmo, encher de computadores os institutos, porém sem a ajuda econômica de Madrid e sem saber muito bem para que...” (EC-2). 


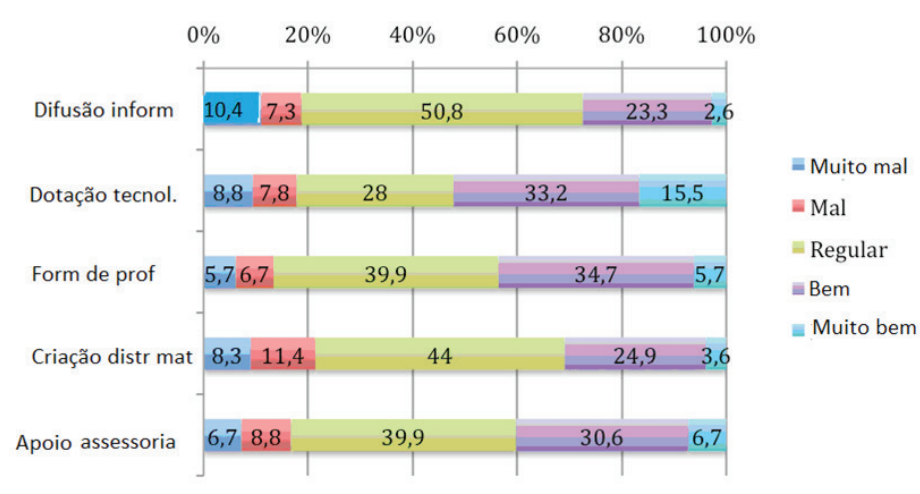

Figura 4 - Avaliação da implantação do CEI.

Os dados expressam que a maioria dos entrevistados qualifica como "regular" ou "bem" as cinco dimensões associadas a implantação do programa CEI. Destaca-se, em coerência com apreciações precedentes, que uns 15,5\% avalie como "muito boa" a oferta de equipamento aos centros. Não é que a porcentagem seja demasiado significativa, porém, é que nas outras quatro dimensões são muito poucos que the concedem a máxima avaliação. Padrão de resposta que, caso contrário, é muito semelhante ao que recolhe a avaliação da amostra estatal entrevistada. De modo que não estamos ante um fenômeno específico do programa da CV, pelo qual cabe perguntar-se por que se dá esta espécie de dissociação.

Tudo parece indicar que se produz uma espécie de lacuna entre as instâncias que desenham e aplicam estes programas "insígnia" e as instâncias receptoras: os centros escolares. É como se os atores tivessem captado com maior nitidez o tangível de tais programas (oferta de computadores, lousa digital e demais), enquanto que o intangível que os acompanha passara mais desapercebido; isto é, a gestão que se faz desde as instâncias administrativas para sua implementação.

\section{Considerações finais}

Como observa Wolcott (2003, p. 133), os trabalhos desta natureza não necessitam "conclusões finais" que enclausuram a análise, pois o trabalho interpretativo nunca se pode dar por encerrado. Antes bem, os parágrafos finais devem recuperar ideias e reflexões sobre os assuntos abordados que tenham chamado a atenção. Exposto em termos que inspiram novas questões e novas formas de prosseguir os trabalhos sobre um tema de estudo com muitas arestas como o presente. Segundo nos chama à atenção Touraine (2002, p. 32), a instrumentalidade das tecnologias atuais contribui para construir um sujeito cujas referências emanam do potencial dessa relação produtiva e não tanto da sociedade em que vive. Em relação ao nosso campo de estudo, essa relação suscita algumas reflexões que expomos agora:

10) O programa de TT que nos ocupa se centra na oferta de equipamentos e não tanto nas necessárias estratégias de acompanhamento, promovidas estas por instâncias de diferente destacamento administrativo ou entidades privadas. Fato que 
dificulta em alto grau a coordenação das atuações, o que suscita desconserto e certo rechaço entre os professores por considerarem o projeto "politizado".

$\left.2^{\circ}\right)$ É consubstancial com a TT gerar inovação, tanto nos processos como nos produtos, sobre os que se aplicam a tecnologia incorporada. Contudo, a percepção que se tem desde os CEI é que nem as práticas nem os resultados mudam muito, salvo significativas exceções. E é o caso do sistema escolar, em que a TT só afeta aos artefatos e não ao conhecimento em que se fundam as inovações. $\mathrm{O}$ uso mais generalizado e melhor avaliado é o relativo aos procedimentos de gestão econômica e administrativa.

$3^{\circ}$ ) As organizações desenvolvem tecnologias próprias para lograr seus objetivos, tecnologias nem sempre compatíveis com as transferidas. Não só se rompe o espaço, o tempo e os protocolos de atuação, se não também os de controle, autoridade, autonomia, âmbitos de responsabilidade, estrutura das relações laborais ou as condições nas quais se realiza a atividade. Aspecto que nos CEI é muito chamativo e de grande interesse para seguir analisando.

Parece claro que a TT provoca nos CEI uma mudança de posição social no serviço que presta, na medida que estes centros são considerados mais "avançados" que o restante, e inerente a isto, uma "mudança de paradigma" no modelo de ensino. Propõem já muitas tarefas on-line: exercícios de classe, realização e avaliação de trabalhos, comunicação com pais, etc. Circunstância que tem importantes implicações políticas e pedagógicas no que tange ao caráter público do sistema escolar, extremo a analisar em futuros trabalhos.

\section{Referências}

ACEYTUNO, M. T. P.; CÁCERES, F. R. C. Los modelos europeos de transferencia de tecnología universidad-empresa. Ponencia presentada a la XIII Reunión de Economía Mundial, 2011. Disponível em: <http://xiiirem.ehu.es/es/programa-detallado>. Acesso em: 15 fev. 2012.

ALCAIDE CASTRO, M. Las nuevas formas de organización del trabajo. Madrid: Akal, 1982.

ANTUNES, R. La nueva morfología del trabajo y sus principales tendencias: informalidad, infoproletariado, (in)materialidad y valor. Sociología del trabajo, n. 74, p. 47-68, 2012.

BARQUÍN, J. et al. Los datos de las TIC en los centros. In: SOLA, M.; MURILLO, J. F. (Coords.). Las TIC en la Educación. Realidad y expectativas. Informe anual 2011. Madrid: Fundación Telefónica, 2011.

BUCKINGHAM, D. Youth, identity, and digital media. Cambridge: MIT Press, 2008.

CALVINO, I. As cidades invisíveis.São Paulo: Biblioteca Folha, 1972.

CASTELLS, M. La galaxia internet. Madrid: Areté, 2001.

COTEC. Tecnología y innovación en España. Informe COTEC 2011. Madrid: COTEC, 2011.

DURALL, E. et. al. Perspectivas tecnológicas: educación superior en Iberoamérica 2012-2017. Austin, Texas: The New Media Consortium, 2012. Disponível em: <http://openaccess.uoc.edu/ webapps/o2/bitstream/10609/17021/1/horizon_iberoamerica_2012_ESP.pdf>. Acesso em: 23 mai. 2013. 
GARCÍA del DUJO, A. et al. Análisis del tiempo en los entornos virtuales de formación. Teoría de la educación, p. 111-130, 2010.

GURRUTXAGA, A. A. Recorridos por el cambio, la innovación y la incertidumbre. Bilbao: Servicio Editorial de la Universidad del País Vasco, 2010.

JIMÉNEZ, J. M. Aspectos de la eficiencia en la transferencia de tecnología. Revista de Investigación en Gestión de la Innovación y Tecnología, 2003. Disponível em: <http://www. madrimasd.org/revista/revista14/>. Acesso em: 23 mar. 2012.

JOHNSON, S. Las buenas ideas. Una historia natural de la innovación. Madrid, Ediciones Turner, 2011.

LAM, A. Tacit knowledge, organizational learning, societal institutions: and integrated framework. Organization Studies, n. 21, p. 487-513, 2000.

LANIER, J. Personas desaparecidas. Claves de razón práctica, v. 218, p. 68-74, 2011.

MESSARIS, P. Visual Literacy: image, mind and reality. San Francisco: Westview Press, 1994.

MOMINÓ, J. M. et al. La escuela en la sociedad red. Internet en la educación primaria y secundaria. Barcelona: Ariel, 2008.

PANIAGUA FUENTES, J. (Dir.) Libro Blanco de la enseñanza secundaria. Comunidad Valenciana 1998-2007. Valencia, UNED-Alzira-Valencia y Generalitat Valenciana, 2010.

PEDRÓ, F. Tecnología y escuela: lo que funciona y por qué. Documento básico. XXVI Semana Monográfica de la Educación, 2011. Disponível em: <http://www.fundacionsantillana. com/>. Acesso em: 12 jan. 2012.

PEIRATS, J.; SAN MARTÍN, A. (Coords.). Tecnologías educativas 2.0. Didáctica de los contenidos digitales, Madrid: Pearson, 2011, p. 27-46.

PINTO, H. Instituciones, innovación y transferencia de conocimiento: contribuciones de los estudios sobre las variedades de capitalismo. Arbor. Ciencia, Pensamiento y Cultura, p. 31-47, 2012.

QUINTANILLA, M. A.; ESCOBAR, M. et al. Scientific and technological culture in ESO texbooks. La cultura científica y tecnológica en los libros de texto de la ESO. Salamanca: Universidad de Salamanca, 2011.

RUBIRALTA ALCANIZ, M. Transferencia a las empresas de la investigación universitaria. Descripción de los modelos europeos. Madrid: Fundación COTEC, 2004.

SAN MARTÍN, A.; SALES, C.; PEIRATS, J. Los programas electorales del 14-M y la migración tecnológica hacia el sistema escolar. Revista de Educación, 342, enero-abril 2007, p. 529-552. Disponível em: <http://www.revistaeducacion.mec.es/re342/re342_24.pdf〉. Acesso em: 12 jan. 2012.

SIGALES, C.; et al. La integración de Internet en la educación escolar española: situación actual y perspectivas de futuro. Informe de investigación. Madrid, UOC-Fundación Telefónica, jul. 2008. Disponível em: <http://www.uoc.edu/in3/integracion_internet_educacion_escolar/esp/ pdf/informe_escuelas.pdf $>$. Acesso em: 12 jan. 2012.

STAKE, R. E. Investigación con estudio de casos. Madrid: Morata, 2010.

STIGLITZ, J. E. El precio de la desigualdad. Madrid: Taurus, 2012.

TOURAINE, A. La sociedad desestructurada, en VV.AA. Teorías para una nueva sociedad. Madrid: Fundación Marcelino Botín, p.17-46, 2002.

WOLCOTT, Harry. F. Mejorar la escritura de la investigación cualitativa. Medellín: Editorial Universidad de Antioquia, 2003. 


\section{Notas}

${ }^{1}$ Mais informações disponíveis em: <http://www.oecd.org/>. [Nota de tradução].

${ }^{2}$ A Agenda de Lisboa ou Processo de Lisboa refere-se a um plano de desenvolvimento estratégico da União Europeia, com o objetivo de promover a economia dos países membros na economia do conhecimento mais competitiva e dinâmica do mundo, antes de 2010. No entanto, estudos tem mostrado certo atraso quanto à inovação nas tecnologias de informação e de comunicação (TIC), em relação aos Estados Unidos e Japão, daí, a ênfase à inovação centrada na geração de conhecimento e sua transferência, ou seja, a TT como motor da economia. [Nota de tradução].

${ }^{3}$ Estudo derivado do Projeto EDU2010-17037 (Plan Nacional de I+D+i): As politicas de um «computador por criança» na Espanha. Visões e práticas dos professores ante o programa Escola 2.0. Uma análise comparada entre comunidades autônomas.

${ }^{4}$ Projetos de I+D+i são parques científicos, cuja responsabilidade, por meio de grupos de investigação é gerar e transferir o conhecimento. [Nota de tradução].

5 “....assume como um processo central para a inovação e o desenvolvimento”. NT.

${ }^{6} 93 \%$ dos alunos com 15 anos de idade na OCDE frequentam uma escola onde eles têm acesso a um computador e quase o mesmo percentual (92,6\%) também têm acesso à Internet” (PEDRÓ, 2011, p. 17...).

7 "A tecnologia não é utilizada em todas as matérias com a mesma intensidade e, por conseguinte, existe uma elevada percentagem de matérias nos quais o nível de integração é praticamente inexistente ...”.

${ }^{8} \mathrm{Em}<\mathrm{http} / /$ www.ite.educacion.es/es/escuela-20> se pode consultar suas características mais relevantes. Acesso em: 16 nov. 2011.

${ }^{9}$ LliureX é uma distribuição Linux, baseada em software livre no sistema educativo da Comunidade Valenciana; baseia-se em Edubuntu, desde a versão 7.11; distribuida em valenciano e castelhano. N.T. Disponível em: <http://lliurex.net/home/>. Acesso em: 15 nov. 2011.

${ }^{10}$ Governo Valenciano: conjunto de instituições de autogoverno da comunidade valenciana, espanha.

${ }^{11}$ Corresponde no Sistema Educacional Brasileiro à Educação Infantil, Ensino Fundamental e Ensino Médio, respectivamente. N.T.

${ }^{12}$ Acrônimo que significa: Inovação Tecnológica Administrativa para Centros e Alunos.

${ }^{13} \mathrm{Em}$ : <http://sai.edu.gva.es/>. Acesso em: 21 jan. 2012.

${ }^{14} \mathrm{Com}$ respeito às diferentes edições de congressos relacionados com o programa, pode consultar-se em: <http://congreso.lliurex.net/index_va.php>. Acesso em fev. 2013.

${ }^{15}$ Dados e informes do progresso do projeto de investigação sobre o programa Escola 2.0, podem consultarse em: $<$ http://www.edullab.ull.es/ticse20/>. Acesso em mar. 2013.

${ }^{16}$ A normativa legal da Comunidade Valenciana (Resolução de 29 de junho de 2010, DOCV 6307, de 09/07/2010) contempla esta figura de coordenação, sua designação e o horário de dedicação, porém não suas funções.

** Professor doutor da Universidad de Valencia, Valencia, Espanha.

*** Professor doutor da Universidad de Valencia, Valencia, Espanha. 
Ángel San Martín Alonso - José Peirats Chacón

\section{Correspondência}

Ángel San Martín Alonso - Facultad de Filosofía y Ciencias de la Educación - Dpto. Didáctica y Organización Escolar, Avda. Blasco Ibáñez, 30, 46010 Valencia.

E-mail: angel.sanmartin@uv.es - jose.peirats@uv.es

Recebido em 06 de março de 2015

Aprovado em 30 de abril de 2015 